\title{
Etnopedagogis Kristen Pada Ume Kebubu Masyarakat Dawan di Desa Noenoni Kabupaten Timor Tengah Selatan Nusa Tenggara Timur
}

\author{
Iswanto, Marsi Bombongan Rantesalu
}

\begin{abstract}
Abstrak
Filsafat realisme dalam antopologi memberikan ruang interpretasi kaitan antara produk budaya, nilai, dan perilaku masyarakat. Penelitian ini mengambil data ume kbubu. Secara etimologis, kata ume diartikan sebagai rumah' sedangkan kbubu berarti _bulat‘. Data diperoleh dari hasil observasi dan wawancara sebagaimana penelitian etnografi. Lebih lanjut, masyarakat dengan budaya yang unik menjadi kajian yang menarik untuk ditelaah secara pedagogis atau lebih tepatnya etnopedagogis. Struktur kemasyarakatan yang kuat dan didasari dengan sistem kepercayaan agama asli, menjadi titik pijak fenomena tersebut Nilai-nilai budaya menjadi milik bersama dan diimani dan diwujudkan dalam perilaku. Kabupaten Timor Tengah Selatan adalah salah satu daerah yang terletak di Propinsi Nusa Tenggara Timur. Kabupaten Timor Tengah (TTS) adalah salah satu Kabupaten di Provinsi Nusa Tenggara Timur (NTT). Penelitian ini diadakan di Desa Noenoni Kecamatan Oenino. Kata Noenoni berasal dari kata Noe artinya sungai dan Noni artinya Tempati. Jadi Noenoni berarti tempat yang berada di pinggiran sungai atau kali. Pada umumnya semua Desa yang berada di Kecamatan Oenino sebagian besar berada di dataran tinggi termasuk juga Desa Noenoni. Luas wilayah Desa Noenoni adalah $1800 \mathrm{Ha}$. Kontruksi ume kbubu secara simbolik, diinterpretasi sebagai simbol hubungan manusia, alam dan langit. Persepsi masyarakat Dawan menandai alam atau bumi sebagai tuhan dengan sebutan uis pah manifu sedangkan langit dikenal dengan adikrodrati uis neno. Berdasarkan hasil penelitian ada tiga nilai pedagogis Kristen dalam struktur Ume Kbubu yaitu: nilai religius, nilai sosial dan nilai budaya. Temuan baru dalam penelitian ini ialah struktur ume kbubu memberikan keseluruhan pandangan sosial-budaya masyarakat Dawan. Paradigma ini bukan hanya ada dalam khazanah budaya tetapi dapat diinterpretasikan dalam nilai pedagogis Kristen dengan melihat kesamaan fitur dan ajaran Kristiani.
\end{abstract}

Kata Kunci: Ume Kbubu, Etnopedagogis, Dawan

\section{Latar Belakang}

Hakekat manusia sebagai mahluk ciptaan Tuhan hidup dalam lingkungan dengan paradigma yang terbentuk berdasarkan lingkaran sosialbudaya. Pemahaman yang kompleks menempatkan produk budaya tidak hanya sekedar hasil cipta tetapi di dalamnya keseluruhan paradigma tersebut berada. Pemahaman ini terkait erat dengan filsafat realisme dalam antropologi (Iswanto, 2018).

Nilai-nilai pedagogis atau pendidikan memiliki fungsi yang sama dengan pendidikan moral dan pendidikan akhlak. Tujuannya adalah membentuk kepribadian seseorang untuk menjadi lebih baik, menjadi warga masyarakat dan warga Negara yang baik. Adapun karakter manusia yang baik, warga masyarakat yang baik 


\section{JURNAL PENDIDIKAN AGAMA KRISTEN}

dan warga Negara yang baik bagi suatu masyarakat.

Konstruksi bangunan adalah sesuatu yang direncanakan atau ditata sebaik mungkin sebelum mendirikannya, dalam hal ini konstruksi bangunan yang dimaksud adalah buatan manusia itu sendiri yang terstruktur dan tertata rapih yang mempunyai atap, dinding dan sejenis lainnya. Selain itu didirikan secara permanen di atas tanah yang berukuran sesuai dengan yang diinginkan. Bangunan harus ditata sebaik mungkin sesuai dengan ukuran yang sudah ditentukan.

Bangunan juga memiliki beragam bentuk, ukuran dan fungsinya dan tahan terhadap cuaca (Van de Ven 1997:30). Selanjutnya (Handler 1870:3) menjelaskan bahwa konstruksi bangunan merupakan suatu seni yang dibuat oleh seseorang menggunakan akal budinya yang tertata sebaik mungkin. Orang yang sudah memiliki keahlian khusus dan ia sudah mempelajari sebelumnya serta ia sudah menguasai teknik-teknik sebelum untuk membuat bangunan tersebut, dalam hal ini bahwa kesatuan antara pencipta ruang yang disebut seniman dalam membangun suatu bangunan tertentu.

Kabupaten Timor Tengah Selatan adalah salah satu daerah yang terletak di Propinsi Nusa Tenggara Timur. Untuk menuju Timor Tengah Selatan kita harus menempuh perjalanan darat sekitar 3 jam dari kota Kupang, baik menggunakan mobil, maupun sepeda motor. Kabupaten Timor Tengah Selatan yang kaya akan berbagai macam kebudayaan, salah satu kebudayaan yang masih terpelihara sampai sekarang adalah kebudayaan bangunan Ume Kbubu (rumah bulat).

Ume Kbubu merupakan salah satu bangunan yang ada di Pulau Timor khususnya Desa Noenoni Kecamatan Oenino Kabupaten Timor Tengah Selatan, dan bangunan ini dikenal sangat kuat jika dibandingkan dengan bangunan-bangunan yang lain. Bangunan Ume Kbubu tahan terhadap tanah longsor atau hujan badai. Berbicara tentang Ume $K b u b u$ memiliki nilai pedagogis yang sangat bermakna yang harus terus terpelihara secara turun temurun sejak dari nenek moyang kita ada.

Berdasarkan latar belakang masalah di atas tujuan penelitian ini ialah mengkaji dan mendeskripsikan etnopedagogis Kristen pada Ume Kbubu masyarakat Dawan di Desa Neononi, Kecamatan Oenino, Kab. TTS.

\section{Teori}

Konsep Etnopedagogis mengacu kepada pembelajaran pengetahuan secara praktis yaitu ketrampilan nyata dan pengalaman nilai-nilai kehidupan. Secara rill, konsep rumah venakular (rumah adat) dapat menjadi contoh pembelajaran bagi masyarakat dan generasi berikutnya walaupun tidak secara sistematis dan terstruktur seperti konsep pedagogis modern. Selanjutnya, (Louis 1987:20) ia membedakan nilai pedagogis menjadi dua bagian yaitu nilai intrinsik yang dimaksud nilai intrinsik adalah nilai yang sudah ada atau sudah dibuat sebelumnya. Sedangkan nilai 


\section{JURNAL PENDIDIKAN AGAMA KRISTEN}

instrumental adalah sesuatu yang dengan sengaja dibuat untuk manusia dan memiliki suatu tujuan tertentu.

Berbeda dengan (Giddens 1995:17) ia berpendapat bahwa nilai adalah suatu ide yang dimiliki oleh seseorang maupun sekelompok orang tentang apa yang hendak layak dipakai atau dilakukan oleh sekelompok orang tersebut. Baik itu yang berkaitan dengan hal baik maupun yang berkaitan dengan hal buruk.

Berdasarkan beberapa pendapat para ahli di atas, dapat disimpulkan bahwa nilai merupakan suatu gagasan yang berdominan tinggi yang ada dalam diri seseorang maupun sekelompok orang dan tak dapat dipisahkan oleh siapapun. Untuk dapat menerapkannya dalam kehidupan setiap hari baik itu sesuatu yang berkaitan dengan hal baik maupun yang berkaitan dengan hal buruk. Dengan demikian, ada beberapa nilai yang ada dalam kehidupan masyarakat antara lain: nilai religius, nilai sosial, nilai moral atau nilai budaya.

\section{Pembahasan}

\subsection{Struktur Ume Krbubu}

Model arsitektur yang
digunakan berciri arsitektur vernakular. Arsitektur vernakular adalah gaya arsitektur yang dirancang berdasarkan kebutuhan lokal, ketersediaan bahan bangunan, dan mencerminkan tradisi lokal. Konsep arsitektur vernakular dibuat oleh masyarakat lokal berdasarkan kearifan lokal tanpa melibatkan rancang bangun arsitektur profesional. Arsitektur vernakular sangat bergantung pada kemampuan mendisain dan tradisi pembangunan lokal. Istilah vernakular berasal dari kata vernaculus di Bahasa Latin, yang berarti "domestik, asli, pribumi", dan dari Verna, yang berarti "budak pribumi" atau "budak rumah-lahir". Model arsitektur ini pada dasarnya dirancang untuk mudah digunakan dan berorientasi pada bangunan tempat tinggal.

Arsitektur vernakular memiliki konsep yang sangat terbuka dan komprehensif. Arsitektur vernakular merupakan istilah yang juga merepresentasikan arsitektur primitif atau asli, arsitektur adat, arsitektur leluhur atau tradisional, arsitektur pedesaan, arsitektur etnis, arsitektur informal, atau arsitektur tanpa tenaga arsitek profesional.

Gaya arsitektur vernakular masyarakat Dawan dipengaruhi oleh berbagai aspek berbeda, mulai dari perilaku manusia hingga kondisi lingkungan, yang membuat bentuk bangunan menjadi berbeda-beda tergantung fungsinya. Salah satu pengaruh paling besar adalah ikim dari daerah dimana Desa Dawan terletak di lembah di atas pergunungan yang tertutup oleh pepohonan yang sangat rindang. Bangunan di iklim demikian akan menggunakan jendela yang berukuran kecil atau sama sekali tidak ada. Sebaliknya juga beberapa bangunan menggunakan kontruksi bangunan beriklim hangat yang cenderung dibangun dengan material yang ringan dan terbuka. 


\section{JURNAL PENDIDIKAN AGAMA KRISTEN}

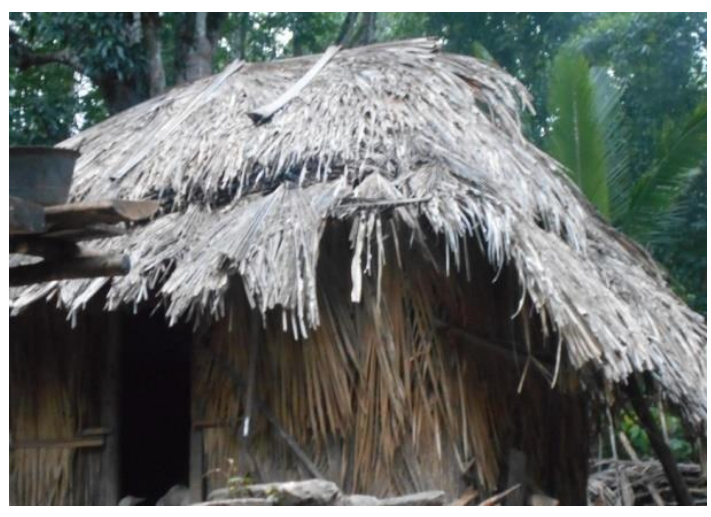

Gambar l Rumah Tinggal

Masyarakat Dawan (Ume to ana),

Foto diambil 18-06-2018

Rumah tinggal masyarakat Dawan berbentuk segi empat sederhana dengan atap jerami. Selain ume to ana juga ada rumah tinggal yang dibuat lebih modern dengan menggunakan atap dari seng. Rumah tinggal terdiri dari tiga ruang yaitu ruang berkumpul, kamar tidur dan ruang makan. Ume to ana rumah tinggal berdekatan dengan rumah bulat "ume kbubu".Rumah ini juga

dikenal dengan istilah rumah perempuan ,ume bife".

Tipologi bangunan „ume kbubu" berbentuk bundar. Luasnya bangunan tergantung pada kebutuhan pemiliknya. Rancang bangun rumah bulat _ume kbubu" menggunakan teknik

sambung ikat dengan memanfaatkan tanam-tanaman dengan batu bundar. Teknik ini menjadi ciri rumah venakular. Secara struktur tingkatan bangunan, rumah ini terdiri dari dua tingkat, yaitu dapur atau tempat memasak dan tingkatan di atasnya yang digunakan untuk menyimpan jagung hasil panen. Pada tingkat dasar yang digunkan untuk memasak juga dapat digunakan untuk beristirahat dan ritual.
Struktur rumah bulat ume kbubu" dimulai dari bagian bawah pondasi „baki" yang dibentuk dari batu kali ceper yang disusun membentuk lingkaran sesuai dengan luasnya. Tinggi pondasi dari permukaan tanah antara 20 $\mathrm{cm}-40 \mathrm{~cm}$. Batu ceper yang dipilih adalah batu yang sangat kuat sehinggadapat menopang bangunan di atasnya. Ketinggian pondasi ini juga berfungsi sebagai penahan air dan mencegah binatang pengerat atau hewan lainnya untuk masuk. Bagian atas pondasi dibuat lantai "nijan" dari tanah yang diurung diatas/ i dalam fondasi yang sudah berbentuk (bundar). Strukur pondasi bulat dengan lantai yang dipadatkan dan sambungan ikatan membuat setruktur bangunan "ume kbubu" lebih tahan gempa karena dapat meredam gesekan antar sambungan dengan lebih baik jika dibandingkan dengan rumah persegi dengan sambungan permanen.

Bagian selanjutnya disebut dengan tiang "ni". Tiang yang menghubungkan antar lantai dan sambungan kayu di atasnya disebut $n i$ anaf. Tiang ini terdiri dari empat buat kayu besar yang ditancapkan secara simetris pada empat sisi. Ni anaf harus tertancap secara dalam dan sangat kuat. Secara arsitektur ni anaf berfungsi sebagai penyannga tingkat ke dua. Jarak antara tiangnya juga bervariasi, namun rata-rata antara 1,5-2,5 m. Bentuk tiang diambil dari alam dan langsung digunakan tanpa dibentuk lagi, hanya dirapikan. Tiang ini dipilih yang tegak lurus dan bercabang pada bagian atas yang mana nanti berfungsi untuk menopang "suit". Jenis kayu yang digunakan antara 


\section{JURNAL PENDIDIKAN AGAMA KRISTEN}

lain : kayu merah atau kayu putih. Tinggi tiang ni anaf", makin dekat dengan pintu makin tinggi hingga kira - kira 1,25 m, sedangkan yang terpendek yang terjauh dari pintu $60-80 \mathrm{~cm}$. Diameter tiang antara $10-15 \mathrm{~cm}$.

Ketinggian tingkat dasar hanya setinggi orang dewasa dan dihubungkan dengan sebuah tangga. Pada tingkat ke dua terdiri dari dua penopang "suit" yang diletakan melintang di atas ni anaf. Teknik ikatan gunakan dalam sambungan ni anaf ke suit. Pada prinsipnya suit berfungsi sebagai segmen perhubungan dengan bagian di atasnya. Prinsip tegak pada tiang ni anaf diubah menjadi melintang dengan menambah dua batang tiang suit. Selain sebagai segmen penghubung suit juga berfungsi sebagai alas ikat bagian melintang lainya yang disebut nomaf. Tiang nomaf dipakai sebagai tumpuan utama dari bangunan secara keseluruhan dan juga sebagai tumpuan untuk meletakan balok-balok loteng. Tiang ini juga meneruskan semua gaya-gaya vertikal ke tanah. Nomaf harus diikatkan sangat kuat pada suif. Nomaf juga berfungsi sebagai dasar lantai pada tingkat atas dari ume kbubu. Teknik berlapis pada tingkat atas akan memperkuat alas yang nantinya digunakan untuk menyimpan jagung dalam jumlah yang banyak (persediaan satu tahun, hingga masa panen berikutnya). Penghubung tingkat dasar dan tingkat atas pada ume kbubu menggunakan tangga "elak". Tangga yang dimaksudkan disini adalah tangga yang digunakan untuk naik ke loteng. Elak ada bermacam-macam bentuknya yaitu tangga berlubang elak ma"bola, terbuat dari sebatang kayu yang dilubangi empat sampai lima lubang. Selain itu ada juga yang disebut tangga bambu "elak se"at" yakni sebuah bambu

yang dilubang $4-5$ lubang sebagai pijakan naik. Elak Haunua, terdiri dari dua batang bambu yang dihubungkan dengan beberapa kayu pendek sekaligus sebagai anak tangga.

Tiang vertikal nomaf diikat lagi dengan enam buah "tunis" dengan posisi membujur dan melintang terhadap kayu penopang "nomaf". Struktur suit diikatkan pada nomaf dan tunis membentuk liga lapisan yang kokoh yang tidak hanya menopang tingkat atas dari ume kbubu tetapi menjadi pemberat dan pengokoh tiang ni anaf. Lapisan melintang membujur yang diikat sangat kuat sangat diperlukan sebagai penopang berat atap yang cukup berat. Kontruksi atap disanggah oleh sebuah tiang vertikal yang disebut tuni. Posisi tunis ditenga diameter lingkar lantai dan diletakan pada tingkat atas. Tiang penopang atap "tunis" berdiri dengan sebuah kayu alas tiang tegak sebagai pusat atap disebut "pauf" yang diikat dari alas kayu yang sejajar dengan "tunis". Tiang ini diletakan dibaian tengah-atas balok loteng. Umlahnya satu (1) buah. Pada bagian bawah diberi takikan untuk memasukannya dalam Tunis, yang kemudian diperkuat dengan ikatan. Sedangkan bagian atas bercabang dan berfungsi untuk menopang balok bubungan. Dinding "niki". Dinding dipasang melingkari tiang "ni ana". Beberapa kayu atau bilah bambu melintang terdiri dari dua jalur diikatkan pada kayu atau bambu 


\section{JURNAL PENDIDIKAN AGAMA KRISTEN}

melintang sekaligus merupakan perkuatan pada dinding. Tinggi dinding $\pm 0,50-0,80 \mathrm{~m}$. Semakin dekat ke pintu semakin tinggi, dindingnya sampai $100 \mathrm{~cm}$. Bahan dinding dipilih dari beberapa jenis bahan antara lain : papan, bambu cincang, batangt pinang cincang, pelepah gewang, kulit kayu dan sebagainya. Bagian bawah atau ujung dinding dimuati diatas batu dengan tujuan agar tidak mudah rusak oleh rayap atau air. Bagian atap disebut humusu dibuat membujur hingga hampir menyentuh tanah. Atap berbentuk kerucut sebagai akibat dari bentuk denah dan rangka atap. Puncak atap mempunyai dua bentuk yakni bulat (seperti sanggul wanita) dan pelana/palungan terbalik. Bentuk bundar bulat atau kerucut secara arsitektur akan melindungi dari panas datau udara dingin.

Konstruksi rangka atap pada ume kbubu terdiri dari (1) nono ana" atau neu" nono yang terdiri dari kayu-kayu kecil (cemara) yang berdiameter antara 2-4 cm yang diikat menjadi satu kesatuan yang berbentuk lingkaran. Neu nono ini bisa berfungsi sebagai kerangka atap dan sebagai rangka pengikat homusu. Atap dipasang melingkari pada seluruh bangunan dengan bertumpu pada tiang-tiang utama ni anaf" kemudian diikat dengan tali. (2) Nono tetu adalah bagian atap yang menggunakan bahan dan berdiameter sama dengan nono ana" tapi ukuran ikatannya sedikit lebih kecil. Fungsi dari nono tetu adalah memberikan bentukan melingkar pada atap bagian tengah. (3) Nono nifu atau sering disebut nono sene adalah bagian atap yang berfungsi pemberi bentuk lingkaran pada bagian atas atap. Bahan serta ukurannya sama dengan nono tetu . (4) Suaf adalah sebuah balok bulat dan lurus, berdiameter 5 -7 cm (untuk ume kbubu) yang diletakan/diikatkan di atas semua nono (nono ana", nono tetu, nono, nono sene/nono nifu). Balok berasal dari batang pohon cemara yang lurus dan panjang, utuh, tidak boleh disambung-sambung pada saat dipasangkan. Fungsi suaf adalah : Sebagai pembentuk rangka atap, dan sebagai tempat untuk mengikatkan takpani. (5) Takpani adalah batang - batang kecil cemara berdiameter 2-3 cm yang diikatkan arah melintang terhadap suaf. Jarak antar takpani 30-40 cm. Fungsi takpani adalah sebagai tempat untuk mengikatkan alang alang. (6) Penutup Atap menggunakan alang - alang hun'.

Bayi yang baru dilahirkan sebelum empat hari akan tinggal dengan ibunya di rumah bulat "ume kbubu" dan dihangatkan dengan api dari pembakaran dapur. Asap dari pembakaran juga berfungsi sebagai pengawet bahan makanan seperti jagung yang diletakan di tingkat kedua bagunan ume kbubu. Arsitektur ume kbubu pada tingkat dasar terdiri dari dari rangka kayu melingkar dan satu pintu kecil untuk masuk ke dalam. Karena pintu tidak tinggi, sehingga setiap orang yang akan memasuki ume kbubu harus menunduk dengan ukuran pintu yang juga kecil.

Ilustrasi gambar ume kbubu atau ume bife dapat dilihat pada gambar di bawah ini. 


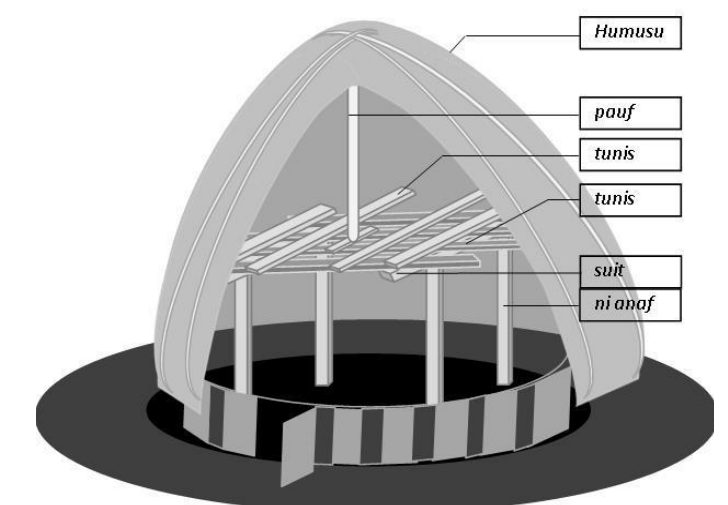

Gambar 2. Rumah Bulat 'ume Kbubu' disebut juga rumah perempuan'ume bife' (Ilustrasi Oleh Iswanto, berdasarkan hasi penelitian)

Istilah rumah bulat =ume $k b u b u$ " juga disebuat sebagai rumah perempuan "ume bife".Alasan penyebutan tersebut terkait dengan fungsinya yaitu sebagai (1) dapur; (2) tempat istirahat sementara perempuan; (3) mengatur bahan makanan yang akan dikelolah dan (4) mengatur bahan makanan untuk satu tahun. Alasan lainya, yaitu simbol budaya. Ume bife disimbolkan sebagai rumah kehidupan. Simbol-simbol tersebut teramati dari (1) tempat menyimpan jagung sebagai bahan makanan pokok; (2) api sebagai simbol kehidupan. Api yang berada di ume bife tidaklah boleh padam atau setidaknya tetap menghasilkan asap.

Secara simbolik ume kbubu atau ume bife dapat diinterpretasi sebagai simbol hubungan manusia, alam dan langit. Persepsi masyarakat Dawan menandai alam atau bumi sebagai tuhan dengan sebutan uis pah manifu sedangkan langit dikenal dengan adikrodrati uis neno. Jika hirarki tersebut digambarkan maka lantai dasar sebagai ibarat dari kehidupan manusia yang akan terus hidup jika bara terus dinyalakan. Simbol jagung pada tingkat atas atau loteng adalah bahan makanan pokok bagi masyarakat Dawan juga sebagai hasil bumi. Representasi tersebut mewakili kehadiran uis pah ma nifu sedangkan yang menjulur hingga ke tanah adalah simbol perlindungan langit yang menyelimuti bumi dan manusia di dalamnya.

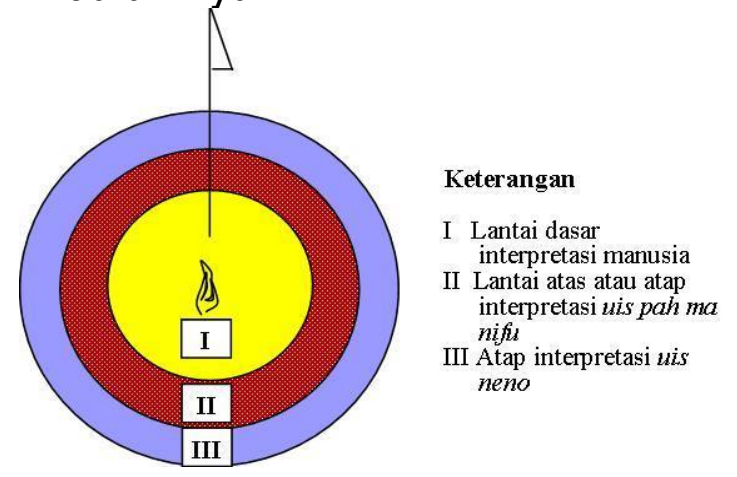

Gambar 3. Interpretasi ume kbubu (Ilustrasi Oleh Iswanto, berdasarkan hasi penelitian)

\subsection{Nilai Pedagogis}

Nilai adalah makna atau isi serta semangat yang tersurat dan tersirat secara fakta dalam bentuk konsep atau teori, dalam hal ini bahwa nilai atau aturan yang berkaitan dengan kehidupan

manusia dan yang dibuat oleh manusia itu sendiri dalam kehidupannya sehari-hari. Berdasarkan hasil penelitian ada tiga nilai pedagogis Kristen dalam struktur Ume Kbubu yaitu: nilai religius, nilai sosial dan nilai budaya. Pemaparan mengenai ketiga sebagaimana di bawah ini.

\section{Nilai Religius}

Nilai religius yang dimaksud merupakan nilai relasi antara manusia dengan Tuhan. Melalui 


\section{JURNAL PENDIDIKAN AGAMA KRISTEN}

nilai religius ini, manusia berhubungan langsung dengan Tuhan melalui doa. Hal ini dapat dilihat pada ungkapan sebagai berikut

UKP.2 Nahun nako ta"uba mepu hit

onen neo Uis Neno

Sebelum kita mulai beraktivitas kita berdoa terlebih dahulu kepada Tuhan'

UKJ.21 Bife kaul nahoin af haim se"e tal leka in mataen na hai mokan neo kle

Jika seorang ibu melahirkan maka akan diasapi kurang lebih dua atau tiga bulan baru diizinkan untuk pergi ke gereja،

Kalimat di atas diambil berdasarkan data pada UKP. 2 dan UKJ.21, yang bertujuan bahwa sebelum masyarakat Desa Noenoni melakukan suatu pekerjaan maka pertama-tama yang mereka lakukan adalah berdoa terlebih dahulu kepada Uis Neno (Tuhan Allah). Mereka berharap dan yakini supaya pekerjaan yang akan mereka lakukan bisa berjalan dengan baik.

Salah satu contoh kecil yaitu ketika masyarakat Desa Noenoni melakukan penanaman jagung atau pada musim panen maka yang pertama-tama mereka lakukan adalah dengan berdoa. Karena mereka meyakini bahwa atas perlindungan dari Tuhan maka hasil panen mereka semakin membaik. Contoh lain lagi yaitu ketika masyarakat Desa Noenoni melakukan bangunan Ume Kbubu (rumah bulat). Mereka berdoa terlebih dahulu bukan untuk meminta harta atau kekayaan tetapi dengan tujuan untuk pekerjaan yang mereka lakukan pada saat itu dapat diselesaikan dengan baik. Jika dibandingkan masyarakat zaman dahulu dengan masyarakat saman sekarang mereka masih tetap melakukan hal yang sama namun masyarakat pada zaman dahulu mereka masih menyembah kepada pohon-pohon atau batu-batu yang mereka yakini. Sedangkan masyarakat modern mereka menyembah kepada Uis Neno (Tuhan Allah) untuk meminta apa yang mereka butuhkan. Tetapi pada kenyataan yang ada juga masyarakat modern ada yang masih menyembah kepada pohon-pohon batu-batu dan sebagainya.

Masyarakat Desa Noenoni mengenal Uis Neno (Tuhan Allah) sebagai Allah pelindung, Allah yang setia, Allah yang sabar dan Allah yang memberi segalanya. (1) yang dimaksudkan dengan Allah pelindung yaitu Dia yang melindungi dalam segala pekerjaan baik itu dalam keadaan susah ataupun senang; (2) Allah yang setia berarti Ia dengan setia menolong dan memenuhi keinginan dari manusia; (3) yang dimaksud dengan Allah maha penyabar yaitu pada saat manusia melakukan apa yang tidak sesuai dengan kehendak Allah. Maka Ia dengan sabar mengampuni kesalahan yang dibuat oleh manusia itu; (4) Allah pemberi segalanya berarti ketika manusia berdoa dan meminta segala sesuatu maka dari situ entah lambat atau cepat Allah akan penuhi. Karena dari ke-empat hal di atas maka masyarakat Desa Noenoni meyakini Uis Neno (Tuhan Allah) sebagai satusatunya Allah yang mereka 


\section{JURNAL PENDIDIKAN AGAMA KRISTEN}

sembah dalam kehidupan seharihari.

Uis Neno (Tuhan Allah) juga dikenal pula sebagai penyelamat artinya bahwa lewat Anak-Nya Yesus Kristus maka Ia telah menyelamatkan umat manusia dari dosa. Dalam diri Allah juga dikenal sebagai tempat perlindungan yang kekal, artinya bahwa hanya Dialah yang dapat melindungi manusia baik itu dalam susah maupun senang. Uis Neno (Tuhan Allah) dikenal juga sebagai Raja yang kekal, yang dimaksudkan kekal berarti Allah itu hidup untuk selama-lamanya, dan kemulian-Nya pun kekal. Tuhan Allah dikenal juga sebagai Allah pemberi hikmat, dalam artian bahwa segala hikmat yang dimiliki oleh manusia itu sematamata adalah pemberian dari Tuhan.

Perempuan Timor pada umumnya berperan sebagai seorang ibu rumah tangga artinya dia yang dapat mengurus semua yang ada di dalam rumah tersebut. Misalnya bertugas untuk memasak, bertugas untuk mengurus anak-anak yang ada di dalam rumah itu dan ketika mengambil makanan di atas loteng maka seorang ibulah yang harus bertugas untuk mengambil makanan tersebut. Akan tetapi, ketika ibu itu mengandung dan tiba saatnya untuk melahirkan maka tugasnya akan diambil alih oleh salah satu orang yang tinggal dalam rumah itu, sampai pada saat ibu itu sudah benar-benar mulai pulih kembali seperti semula baru ia mulai kembali beraktivitas seperti biasanya. Pada saat melahirkan maka ibu bersama bayinya akan diletakkan di atas tempat tidur yang ada di dalam
Ume Kbubu (rumah bulat) yang sudah disediakan, dan akan dibuatlah api yang akan diletakan dekat dengan api untuk mengasapi ibu yang sedang melahirkan itu. Waktu yang dibutuhkan untuk mengasapi ibu yang melahirkan bersama bayinya adalah kurang lebih dua atau tiga bulan sampai ibu tersebut benar-benar pulih kembali baru diizinkan untuk ikut ke gereja. Menurut pandangan masyarakat Desa Noenoni, gereja adalah sonaf knino (tempat kudus) atau tempat berkumpulnya orang percaya untuk beribadah kepada Tuhan. Selain itu gereja dipandang sebagai tempat kudus yang harus dijaga dan ditata sebaik mungkin. Biasanya masyarakat Desa Noenoni ketika sudah panen maka hasil panen mereka sebagiannya diambil untuk dibawa ke gereja sebagai tanda ucapan syukur atas apa yang mereka peroleh selama satu tahun.

\section{Nilai Sosial}

Nilai sosial yang dimaksud berkaitan dengan bagaimana masyarakat Timor terkhususnya masyarakat Desa Noenoni menata kehidupan mereka dengan rasa tanggung jawab dan suka tolongmenolong dalam melakukan suatu pekerjaan. Yang sering dilakukan oleh masyarakat Desa Noenoni adalah ketika mereka melakukan suatu pekerjaan maka hal yang mereka lakukan adalah bertanggung jawab dan saling menolong satu dengan yang lainnya.

Karena menurut mereka manusia tidak bisa hidup sendiri tanpa bantuan dari orang lain oleh karena itu manusia saling 
membutuhkan satu dengan yang lainnya, atau di sisi lain manusia tidak bisa hidup seorang diri. $\mathrm{Hal}$ ini dapat dilihat pada ungkapan sebagai berikut:

UKJ.1 Kaul bale la hit taloetan ka mnela fa af hit hani

Tempat yang kita
siapkan
harus
rata،

UKJ.2 Ha tasop mepu nok alekot

Supaya pekerjaan yang kita

kerjakan bisa

selesai"

UKJ.4 Ume Kbubu atefe kat pakef balek mas hit paek hun

Rumah

bulat

diatap

menggunakan alang-

alang،

UKJ.6 Hit neo in nono lana kbubu

lakleok okat na nait in aon ma nasaeba

Nono dilipat sebulat mungkin sehingga bisa letakkan rumah bulat"

UKJ.11 Tamu amnemat lana kaul fomili af in taman fin neo ume kbubu in nanan natuin in fain atuntakus neo bife amahonit lana

Tamu yang datang sebagai keluarga maka akan masuk ke dalam rumah bulat karena keluarga yang dimaksud sebagai pendukung atas ibu yang melahirkan'

UKJ.13 Ume Kbubu atefe ka ta"aiti

tisnef ka tanebet tisnef

Atapan rumah bulat tidak terlalu tinggi dan tidak terlalu rendah'

UKJ.22 Salit atpaek pana hanati tatao mnahat ma tatolo lais mae

Tujuan memakai loteng untuk menyimpan makanan'

Kata yang bernilai sosial pada kalimat diambil berdasarkan data UKJ. 1, UKJ. 2, UKJ.4, UKJ.6, UKJ.11, UKJ.13, UKP.19 dan 


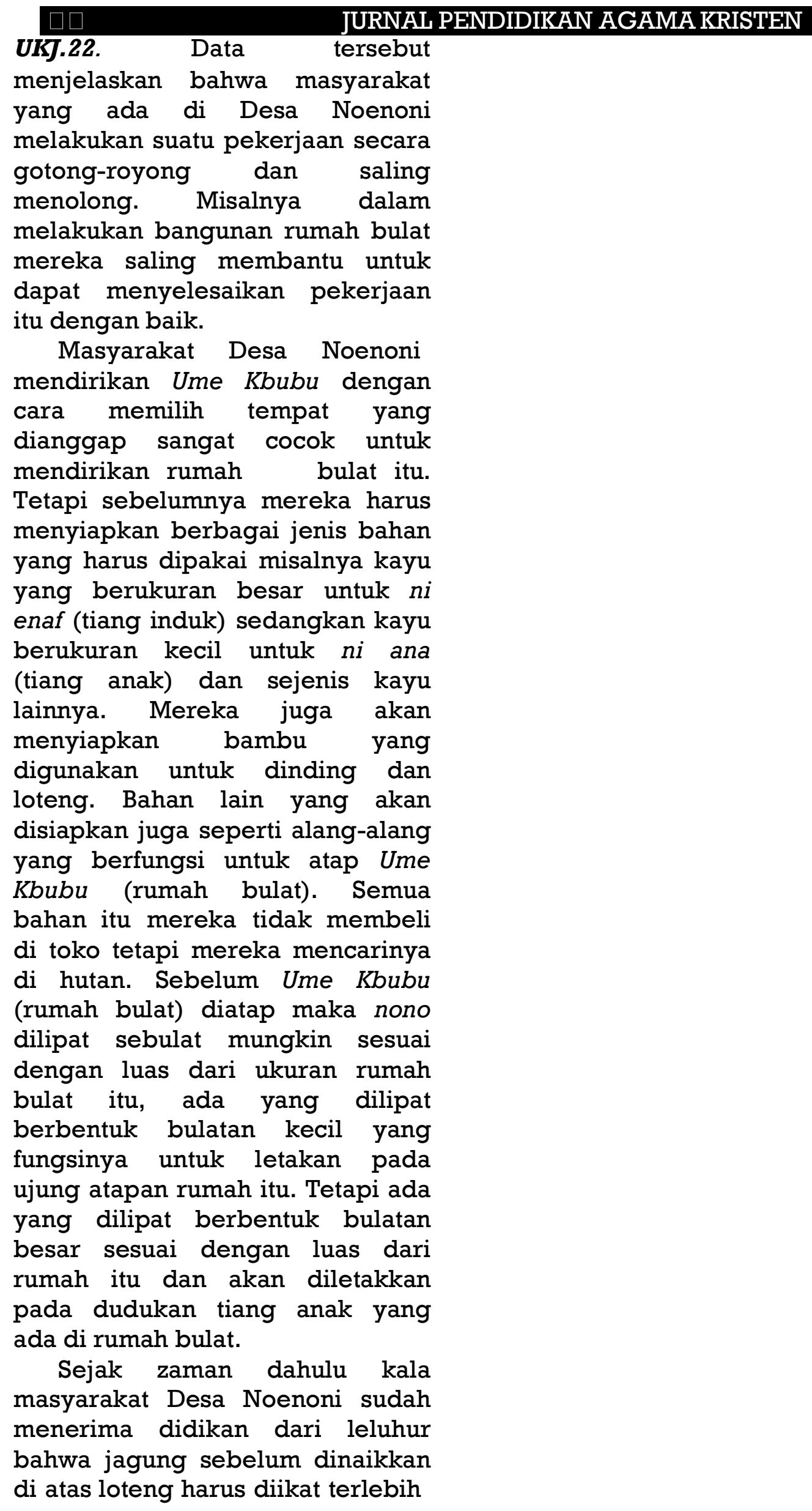




\section{JURNAL PENDIDIKAN AGAMA KRISTEN}

dahulu. Namun untuk mendapatkan jagung maka mereka harus melalui berbagai proses, misalnya menyiapkan bibit jagung secukupnya untuk ditanam. Sebelumnya mereka akan menyiapkan kebun yang berukuran semampunya mereka dan kebun itu akan dibersihkan semaksimal mungkin yang akan mereka gunakan untuk menanam segala jenis keperluan mereka. Jagung-jagung yang disiapkan akan ditanam pada musim hujan tiba. Pada penanaman jagung masyarakat Desa Noenoni akan menanam setiap lubang terdiri dari tiga atau empat biji. Dengan adanya penanaman segala jenis makanan yang ada di dalamnya maka mereka akan merawat kebun milik mereka dengan baik sambil menunggu hasil panen tiba.Ikatan jagung itu jika ada yang kecil maka akan digabungkan menjadi dua setelah itu baru diikat, sedangkan jagung yang berukuran besar akan diikat satu-satu. Dalam ikatan-ikatan itupun akan digabungkan lagi menjadi satu yaitu yang disebut nenuf, sedangkan akan dibuat lagi ikatan yang berebentuk haneka setelah itu untuk mengetahui penghasilan selama satu tahun. Masyarakat Desa Noenoni akan menggabungkan jagung-jagung yang berbentuk nenuf dan haneka itu untuk menghitung ke hitungan yang lebih tinggi lagi yaitu bakase (kuda), dan hitungan tuke.

\section{Setelah} mengetahui penghasilan selama satu tahun maka jagung-jagung tersebut akan digantung pada Ume Kbubu (rumah bulat) dan mengasapi sampai kulit jagung berubah warna menjadi kuning. Setelah itu jagung-jagung tersebut disimpan pada loteng dan dikelolah untuk memenuhi kehidupan setiap hari. Menurut masyarakat Desa Noenoni tamu adalah orang yang harus dihargai, jika ada tamu yang datang ke uem tuaf (tuan rumah) dan tamu itu bukan keluarga maka akan diarahkan untuk masuk ke rumah modern atau yang biasanya dikenal sebagai rumah seng. Tetapi tamu yang datang adalah keluarga dari uem tuaf (tuan rumah) itu maka tamu itu dipersilahkan untuk masuk ke Ume Kbubu (rumah bulat). Ketika ada ibu yang melahirkan maka tamu yang datang sebagai keluarga akan dipersilahkan untuk masuk ke dalam Ume Kbubu (rumah bulat). Karena tamu sebagai pendukung atas ibu yang melahirkan itu, dan atas dukungannya maka tamu yang datang akan membawa air atau kayu api atau bisa saja mendukung melalui doa. Kalimat di atas sangat mengandung nilai sosial yang sangat tinggi sehingga harus tetap dilestarikan karena dimanapun manusia berada maka ia sangat membutuhkan orang lain untuk saling bekerja sama atau bergotong-royong.

\section{Nilai Budaya}

Nilai moral yang dimaksud berkaitan dengan bagaimana masyarakat Desa Noenoni menerima ajaran yang telah diberikan oleh nenek moyang mereka sejak zaman dahulu kala dan mau melakukannya. Semua ajaran atau didikan yang diturunkan oleh nenek moyang mereka tetap mengingatnya. Ajaran atau didikan yang dimaksud berupa pemberitahuan yang diberikan oleh nenek moyang maupun hanya dilihat 
langsung oleh penerus-penerus kebudayaan tersebut. Setelah mereka sudah menerima ajaran yang dimaksudkan maka mereka melakukan seperti apa yang sudah diterima dari nenek moyang mereka. Hal ini dapat dilihat pada ungkapan sebagai berikut:

UKJ.5 Nako nan sin nai ma sin be ume kbubu in lo ha kbubu nain kun

Sejak zaman nenek

moyang rumah bulat harus tetap bulat"

UKJ.9 Ume kbubu in eno taktuka natuin nana neo lupit ini haken

Pintu rumah bulat pendek dan sempit karena dilihat dari ukuran dinding

UKJ.10 Ume kbubu in eno afat panat hanati anbaina neo ume naek Pintu rumah bulat diukur tepatnya berhadapan dengan rumah modern'

UKJ.15 Tahoip ai anbi ume kbubu mas afat panat ha ai kais anmaet kaulkat af nek amle"ot neo kit

Api yang ada dalam rumah bulat harus dijaga sehingga tidak mati karna api tersebut mati maka akan membawa malapetaka bagi kita'

UKJ.19 Pena atfutu hanati tahin hit mnahat in ain anbi ton mese in nanan

Jagung diikat supaya kita mengetahui hasil panen selama satu tahun"

UKJ.21 Tabu atse bife af ka telhaif ai abit hala taen natuin af nek amle"ot neo kit, okat af katahanaf neo ai la abit hala taen natuin kaul nai nanua af li"ana panan nanus

Api yang ada di samping tempat tidur tidak boleh 
dilanggar

\section{JURNAL PENDIDIKAN AGAMA KRISTEN}

mengakibatkan malapetaka

bagi kita, dan tidak digunakan untuk memasak'.

Data yang meng-

interpretasikan nilai moral terdapat pada: UKP.4, UKJ.5, UKJ. 9, UKJ.10, UKJ.15, UKJ.19 dan UKJ.21, Hal ini secara umum menggambarkan bahwa masyarakat menerima didikan moral dari leluhur dan melakukannya dalam kehidupan sehari-hari sesuai dengan apa yang sudah diajarkan.

Ume Kbubu (rumah bulat) diatap harus menggunakan alangalang karena jika diatap menggunakan bahan lain selain alang-alang maka kelihatannya tidak baik. Ketika membuat rumah bulat maka orang yang sedang membangun rumah bulat tersebut harus pergi di hutan untuk mencari alang-alang sesuai dengan keperluan yang akan digunakan. Pada zaman dahulu, sejak nenek moyang mereka sudah mengajarkan bahwa Ume Kbubu (rumah bulat) dengan bentuknya yang bulat itu harus tetap bulat karena dilihat dari ukuran pada saat pembuatan rumah bulat tersebut. Pada pintu rumah bulat yang berukuran pendek dan sempit karena dari awal nenek moyang itu ada maka pada saat membuat Ume Kbubu (rumah bulat) mereka mengukur pintu sesuai dengan tingginya dinding dan tiang-tiang yang ada di pinggir rumah itu. Selain itu, setiap orang yang masuk ke dalam rumah bulat maka harus membengkuk serendah mungkin karena ukuran pintu Ume Kbubu (rumah bulat) yang pendek dan sempit itu. Dalam Ume Kbubu (rumah bulat) juga akan dibuatlah 


\section{JURNAL PENDIDIKAN AGAMA KRISTEN}

api yang bertujuan untuk mengasapi makanan-makanan yang ada di dalam rumah bulat. Menjaga rumah supaya tetap hangat dan tidak ada ular yang masuk, dipakai untuk memasak dan akan dipakai juga pada saat ada ibu yang melahirkan.

Pada api tersebut juga akan dijaga sehingga tidak mati, jika demikian maka kayu yang biasa digunakan pada api itu berukuran cukup besar sehingga api tidak mudah untuk mati. Karena nenek moyang mereka mengajarkan bahwa jika api mati dan mereka pergi untuk meminta di orang lain maka akan membawa malapetaka bagi mereka. Sehingga mereka menerima ajaran itu dengan baik dan merekapun menjaga sehingga api tersebut tidak mati. Jika api tersebut matipun pasti masih ada arang-arang yang masih hidup, dan dari arangarang itu mereka akan membuat api seperti semula. Api yang kita buat di dalam Ume Kbubu (rumah bulat) kita tidak dapat menjaganya dengan baik hingga mati maka akan membawa malapetaka yang akan menimpa keluarga tersebut. Keluarga tersebut akan merasa tidak nyaman, dengan adanya malapetaka yang menimpa mereka.

Pada saat ibu melahirkan juga akan ada api yang diletakkan di dekat tempat tidur, gunanya untuk mengasapi ibu yang sedang melahirkan itu. Tetapi pada api yang dekat tempat tidur itu tidak akan digunakan untuk memasak. Kayu-kayu yang dekat tempat tidur itu mereka menggunakan kayu yang berukuran besar, dengan tujuan supaya ibu tersebut bersama bayinya tidak terasa dingin. Menurut masyarakat Desa Noenoni hala (tempat tidur) adalah tempat untuk duduk, beristirahat dan ketika ada ibu yang melahirkan maka akan diletakkan di tempat tidur itu. Maasyarakat Desa Noenoni membuat tempat tidur dari kayukayu yang sudah dipotong rapih sesuai dengan ukuran yang diinginkan.

\section{Simpulan Dan Saran}

Berdasarkan pembahasan di atas, maka peneliti menyimpulkan bahwa nilai-nilai yang terkandung pada bangunan Ume Kbubu ada delapan yaitu sebagai berikut: (1) Nilai religius yang dilihat dari relasi antara manusia dengan Uis Neno (Tuhan Allah). Hal ini membuktikan bahwa masyarakat Desa Noenoni mengakui dan meyakini adanya Tuhan. Masyarakat Desa Noenoni percaya bahwa hanya Tuhanlah yang melindungi mereka dari segala hal misalnya di saat masyarakat Desa Noenoni melakukan suatu pekerjaan maka mereka berdoa terlebih dahulu kepada Uis Neno (Tuhan Allah). Karena mereka percaya bahwa Allah yang melindungi mereka sehingga pekerjaan yang mereka lakukan bisa berjalan dengan baik. (2) Nilai sosial berkaitan dengan bagaimana masyarakat Timor terkhususnya masyarakat Desa Noenoni menata kehidupan dengan suka tolong-menolong. Dalam hal ini berarti bahwa dalam melakukan suatu pekerjaan misalnya bangunan Ume Kbubu (rumah bulat) maka mereka saling membantu untuk dapat menyelesaikan pekerjaan yang mereka lakukan itu. Karena Menurut masyarakat Desa 
Noenoni manusia itu sangat membutuhkan orang lain dalam hidupnya. (3) Nilai budaya yang dapat dilihat dari kelakuan manusia mau melakukannya atau tidak. Hal ini membuktikan bahwa masyarakat Desa Noenoni meyakini bahwa ajaran yang disampaikan oleh nenek moyang mereka itu baik sehingga mereka terus melakukannya. Misalnya ajaran tentang cara mengikat jagung, mereka melihat serta mendengar didikan dari nenek moyang mereka lalu mereka melakukan sesuai dengan apa yang sudah diajarkan. Temuan baru dalam penelitian ini ialah struktur ume kbubu memberikan keseluruhan pandangan sosialbudaya masyarakat Dawan. Paradigma ini bukan hanya ada dalam khazanah budaya tetapi dapat diinterpretasikan dalam nilai pedagogis Kristen dengan melihat kesamaan fitur dan ajaran Kristiani. Dengan demikian, saran bagi peneliti selanjutnya ialah mampu memberikan deskripsi yang lebih spesifik sebagai kajian etnopedagogis Kristen yang lebih luas. 


\section{DAFTAR PUSTAKA}

Amin Shabana. 2017. Toward Community, Environmental, and Sustainable Development Amin Shabana: Religious Tolerance, Indonesian Cinema and Relational Dialectic Proceeding The lst International Conference on Social Sciences University of Muhammadiyah Jakarta, 399-403.

Arikunto,Suharsimi. 2007.Dasar-dasar Evaluasi Pendidikan, Jakarta: Bumi Aksara.

Barthes, Roland. 1985. Mythologies. NewYork: Hill and Wang.

Barthes, Roland.1994. -Myth Todayll, dalam John Storey (Ed.), Cultural Theory and Popular Culture. New York: A Reader, Harvester Wheatsheet.

Barthes, Roland.2001. Mythogies. NewYork: Hill \& Wang.

Barthes, Roland.2004. Mitologi. (Terj. Nurhadi \& Sihabul Millah), Yogyakarta: Kreasi.

Baryadi, Praptomo. 2002.Dasar-dasar Analisis Wacana dalam Ilmu Bahasa.

Berger, Arthur Asa. 1982. Media Analysis Techniques. California: Sage Publications, Beverly Hills.

Bernard, Russel. H. 1994. -The Literature Researchll dalam Research

Method In Anthropology. London New Delhi: Sagé Publication.

Budiman, Manneke. 2004. -Semiotika dalam Tafsir Sastra: Antara Riffaterre dan Barthes ll dalam T.Christomy dan Untung Yuwono, Semiotika Budaya, Penerbit Pusat Kemasyarakatan dan Budaya UI, Jakarta: Pusat Kemasyarakatan dan Budaya UI.

Bungin, Burhan. 2010. Penelitian Kualitatif. Jakarta: Kreasi Kencana.

Connor, Allan O. 1990. -Culture and Communicationll, dalam John Downing, Ali Mohammadi \& Annabele SreberyMohammadi (Eds.), Questioning The Media: A Critical Introduction, California: Sage Publication, Newbury Park.

Cook, G.J. 1994. Discourse and Literature: The Interplay and Mind. Oxford: Oxford University Press.

Corneo, Giacomo dan Olivier Jeanne. 2009.A Theory of Tolerance. London:Johns Hopkins University.

Danesi, Marcel (ed). 2004. A Basic Course in Anthropological Linguistic. Toronto: Canadian Scholar's Press inc.

Eggin, Suzannae. 1994. An Introduction To Systemic Functional Linguistic. London: Pinter Publisher Ltd.

Eliade, Mircea. 1963. Myth and Reality, New York: Harper \& RowUnknownn parameter.

Endraswara, Suwardi. 2003. Metode Penelitian Sastra, Epistomologi, Model, Teori, Dan Aplikasi. Yogyakarta: CAPS.

Eriyanto. 2009. Analisis Wacana.Pengantar Analisis teks Media. Jogyakarta: LKiS.

Fatubun, Raymond dan Romi. 2003. Struktur Sastra Lisan Biak Numfor: Sebuah Kajian Arketip. Jayapura: Universitas Cenderawasih. 


\section{JURNAL PENDIDIKAN AGAMA KRISTEN}

Fautngil, Christ. 1994. Hubungan Folklor dengan Seni Ukir Suku Asmat Dalam Menghadapi Pembangunan Nasional. Seminar Nasional Hasil Penelitian Perguruan Tinggi. Sawangan Bogor 2 s.d. 6 Januari.

Finegan, Ruth. 1979. Oral Tradition and Verbal Arts. London: Chapman and Hall.

Fiske, John. 1990. Introductions to Communication Studies, London: Routledge.

Foley. 1986. Anthropological; Linguistic: An Introduction. Oxford: Blackwell.

Fox, James. 1986. Bahasa, Sastra, danSejarah; Kumpulan KaranganMasyarakatPulau Roti. ILDEP.

Halliday \& Hasan. 1985. Language, Context, and Text : Aspect of Language Interogatve In a Social Semiotic Perspective. Vivtoria: Deakin University.

Halliday, M.A.K. 1977. Language as Social Semiotic: Towards as General Socio-linguistic Theory. Dalam Makalah A. Makkai, V.B., \& Heilman, L. (Eds.). $\quad$ Linguistic At The Cross Road. Padova: Tipografiala Garngola.

Halliday, M.A.K. 1978. Language as Social Semiotic: The Social Interpretation of Language and Meaning. London: Edward Arnold.

Halliday, M.A.K. 1992. Bahasa, Konteks, dan Teks: Aspek-Aspek Bahasa dalam Pandangan semiotik Sosial. Terjemahan oleh Barari. Jogyakarta: Gadjah Mada University.

Hoed, Benny H. 2011. Semiotik \& Dinamika Sosial Budaya. Depok: Komunitas Bambu.

Iswanto, 2018. Supernatural Signification System Amuf on Death Ritual Speech Nen Fen Nahat Neu Nitu in Dawan Society (index tertinggi Thomas Reuthers) International Journal of Linguistics, Literature and Culture (IJLLC), [S.l.], v. 4, n. 2, p. 46-57, mar. 2018. ISSN 2455-8028. Available at: <https://ijcu.us/online/journal/index.php/ijllc/article/view/647 $>$.Date accessed: 14 july $2018 . \quad$ doi: https://doi.org/10.21744/ijllc.v4i2.647..

Iswanto. 2016.Local Marriage System of Dawan Community Depicted through its Speech Ritual. Kawalu: Journal of Local Culture, [S.l.], v. 3, n. 2, p. 1 - 23, dec. 2016. ISSN 2460-4313. Available at: <http://jurnal.uinbanten.ac.id/index.php/kwl/article/view/776>. Date accessed: 14 july 2018.

Iswanto. 2017. Teks Kerja' pada Masyarakat Dawan dalam Menjelaskan Fenomena Tenaga Kerja Migran di NTT. Matheteouo Vol. 4 Ed. September 9, 2017

Iswanto.2011. Sistem Penandaan Religiusitas dalam Tuturan Ritual MasyarakatDawan (tesis).Kupang: UNDANA

Joseph, Campbell. 1988. The Power of Myth, New York: Doubleday.

Kaymenawut Terei Atakam). Tesis Program Magister, Jurusan Antropologi, Universitas Gajah Mada.

Koentjaraningrat. 1985. Pengantar Ilmu Antropologi. Jakarta: Penerbit Rineka Kreasi. 


\section{JURNAL PENDIDIKAN AGAMA KRISTEN}

Kridalaksana. 2008. Kamus Linguistik. Jakarta: PT Gramedia Pustaka Utama.

Larasati, Marietta Bali. 2009. -Mitos Ine Pare" dalam Dinamika Budaya

Agraris Komunitas Etnik Lioll. Tesis. Denpasar: Program Pascasarjana Universitas Udayana.

Manmak, Kaspar and Linggarsari, Dewi. 2008. Folklor On The Rumpun Bisman Of Asmat Community. Yogyakarta: Biograf Publisher.

Mayring, Philipp. 2014.Qualitative content analysis: theoretical foundation, basic procedures and software solution. Klagenfurt. Available on URN: http://nbn-resolving.de/urn:nbn:de:0168ssoar-395173.

Minsarwati, Wisnu. 2002. Mitos Merapi \& Kearifan Ekologi, Menguak Bahasa Mitos Dalam Kehidupan Masyarakat Jawa Pegunungan. Yogyakarta: Kreasi Wacana.

Moleong, Lexy.J. 2005. Metodologi Penelitian Kualitatif. Bandung: Remaja Rosda-karya.

Mulyana. 2005. Kajian Wacana : Teori, Metode dan Aplikasi PrinsipPrinsip Analisis Wacana. Yogyakarta: Tiara Wacana.

Paina. 2010. -Tindak Tutur Komisif Bahasa Jawa: Kajian Sosiopragmatikll. Disertasi. Yogyakarta: Universitas Gadjah Mada.

Poerwadarminta, W. J. S. 1976. Kamus Umum Bahasa Indonesia. Jakarta: PN Balai Pustaka.

Pradopo, Rahmat Djoko. 2003. Beberapa Teori Sastra, Metode Kritik Sastra, dan Penerapannya. Yogyakarta: Pustaka Pelajar.

Ratna, I Nyoman Kutha. 2003. Paradigma Sosiologi Sastra. Yogyakarta: Pustaka Pelajar.

Rantesalu, Marsi Bombongan, and Iswanto Iswanto. "Toleransi Berdasarkan Cerita Rakyat Tallu To Sala' Dadi Di Toraja." BIA': Jurnal Teologi Dan Pendidikan Kristen Kontekstual; Vol 1, No 1 (2018): JuniDO 10.34307/b.Vlil.16, Desember 2018. http://www.jurnalbia.com/index.php/bia/article/view/16.

Rantesalu, Marsi Bombongan, and Syani Bombongan Rante Salu. "PERANAN AGAMA KRISTEN DALAM MENGHADAPI KONFLIK AGAMA DI INDONESIA." Preprint. AgriXiv, October 14, 2019. https://doi.org/10.31220/osf.io/p6bh7.

Ratna, I Nyoman Kutha. 2004. Teori, Metode, dan Teknik Penelitian Sastra. Yogyakarta: Pustaka Pelajar.

Ratna, I Nyoman Kutha. 2011. Antropologi Sastra, Peranan Unsur-unsur Kebudayaan dalam Proses Kreatif. Yogyakarta: Pustaka Pelajar.

Ricoeur, Paul. 1981. Hermeneutics and the Human Science: Essay on Language, Action, and Interpretation. Cambrigde: Cambridge University Press.

Ritzer, George. 2003. Teori Sosial Postmodern (penerj. Muhammad Taufiq). Yogyakarta: Kreasi wacana.

Robert W. Hefner. 2018.Routledge Handbook Of Contemporary Indonesia. New York: Routledge.

Rusyana, Yus. 1975. Peran dan Kedudukan Sastra Lisan dalam Pengembangan Sastra Indonesia. Proyek Pengembangan 
Rusyana, Yus. 1980. "Cerita Rakyat Nusantara". Disampaikan dalam konsorsium Sastra dan Filsafat Fakultas Sastra dan Kebudayaan UGM.

Santosa, Anang. 2011. -Semiotik Sosial Hallidayll dalam Jurnal bahasa dan Seni Tahun 2008. Nomor I. http://google.co.id. diakses tanggal 20 Januari 2013.

Sayekti, Valensi. 2012. Asmat Atakam (Analisis Struktural Levi-Strausse dalam Mitos

Septiyarti, Yemi. 1991. Hubungan Cerita Rakyat dengan Seni Ukir Asmat dan Manfaatnya dalam Pembangunan. The Toyota Foundation.

Septiyarti, Yemi. 1996. Nyanyian Rakyat Waropen. Departemen Pendidikan dan Kebudayaan Direktorat Pendidikan Tinggi. Jakarta.

Sharifian, Farzad. 2011. Cultural Conceptualisations and Language: Theoretical Framework and Applications. Amsterdam: John Benjamins Publishing Company

Shipley, Joseph T. (Ed). 1962. Dictionary of World Literature. New Jersey: Littlefield, Adams \& Co.

Sianipar, Jonner. 2010. -Membangun Papua dengan Formulasi Tradisi Lisanll dalam makalah pada Seminar Bahasa dan sastra dalam rangka Bulan Bahasa dan Sastra tahun 2010, Balai Bahasa Provinsi Papua di Aula Museum Negeri Provinsi Papua, Waena-Jayapura,

28 Oktober 2010.

Stuart (Ed.), 1997. Representation: Cultural Representations and Signifying Practices.London: Sagé Publications.

Sudarman, Dea. 1984. Asmat, Menyingkap Budaya Suku Pedalaman Irian Jaya. Jakarta: Sinar Harapan.

Sudaryanto.1993. Metode dan Aneka Teknik Analisis Bahasa: Pengantar Penelitian Wahana Kebudayaan secara Linguistis. Yogyakarta Duta Wacana University Press.

Sudikan, Setya Yuwana. 2001. Metode Penelitian Kebudayaan. Surabaya: Citra Wacana.

Sudjiman, Panuti. 1990. Kamus Istilah Sastra. Jakarta: Universitas Indonesia.

Suharso dan Retnoningsih, 2005. Kamus Besar Bahasa Indonesia. Semarang: Widya Karya.

Sumaryono, E. 1993. Hermeneutik Sebuah Metode Filsafat. Yogyakarta: Kanisius.

Sutanto, Trisno. 2012. Melampaui Toleransi: Belajar Bersama Walzer. Dalam Demi Toleransi, Demi Pluralisme. Jakarta:Domokrasi Project

Tim Penyusun Kamus Pusat Bahasa.1996.Kamus Besar Bahasa Indonesia. Jakarta: Balai Pustaka,

Tolson, Andrew. 1996. Mediations: Text and Discourse ini Media Studies, London: Arnold.

Wellek, Rene dan Austin Warren. 1989. Theory of Literature. Victoria: Pinguin.

Winick, Charles. 1961. Dictionary of Anthropologi, New Jersey: Littlefied, Adam \& Co, Peterson. 